\title{
The Hydroxylation of Vitamin D on C25 in Thyrotoxicosis: The Role of the Activity of Microsomal Liver Enzymes
}

\author{
Chris G. Velentzas ${ }^{1,2,3}$ \\ ${ }^{1}$ Military Hospital of Athens, Athens, Greece; ${ }^{2}$ Toronto Western Hospital, Toronto, Canada; ${ }^{3}$ University of Athens, Athens, Greece. \\ Email: impression713@yahoo.gr
}

Received April 20 ${ }^{\text {th }}$, 2012; revised May 28 ${ }^{\text {th }}$, 2012; accepted June $17^{\text {th }}, 2012$

\begin{abstract}
Vitamin $\mathrm{D}_{3}$ after its entrance in the organism undergoes hydroxylation on C-25 carbon atom by the action of microsomal liver enzymes giving the metabolite 25 hydroxyvitamin $\mathrm{D}_{3}\left(25 \mathrm{OHD}_{3}\right)$. The function of microsomal liver enzymes is influenced in some specified states by hormones or drugs. It has approved that thyroxin is a potent stimulator of these enzymes while allopurinol suppresses their function. The aim of this issue is to examine $25 \mathrm{OHD}_{3}$ plasma levels in thyrotoxic subjects and in those pretreated with allopurinol on the base of the afford mentioned data. In a first phase $25 \mathrm{OHD}_{3}$ plasma levels were estimated in thyrotoxic subjects against euthytoid healthy controls. In a second phase $\mathrm{lmg}$ vitamin $\mathrm{D}_{3}$ was injected intravenously (i.v.) in thyrotoxic subjects and in healthy euthyroid controls. $25 \mathrm{OHD}_{3}$ plasma levels were measured before and in post injection period in six hours intervals for 48 hours. In a third phase a couple of subjects one thyrotoxic and one euthyroid healthy control pretreated both with allopurinol injected lmg of vitamin $\mathrm{D}_{3}$ i.v. In all studied subjects $25 \mathrm{OHD}_{3}$ plasma levels were measured before and in post injection period in six hours intervals for 48 hours. The pre and post injection $25 \mathrm{OHD}_{3}$ plasma levels measured the size of activity of liver enzyme responsible for bioactivation of vitamin $\mathrm{D}_{3}$. In the first phase was indicated that $25 \mathrm{OHD}_{3}$ plasma levels were lower in thyrotoxic subjects comparing with that of euthyroid healthy controls $(\mathrm{p}<0.001)$. In the second phase was found that the bioactivation of vitamin $\mathrm{D}_{3}$ in thyrotoxic subjects was 2.5 to 8 times faster comparing with euthyroid healthy controls. In the third phase was shown that allopurinol decreases the activity of liver enzymes function as regard the bioactivation of vitamin $\mathrm{D}_{3}$. The bioactivation of vitamin $\mathrm{D}_{3}$ is accelerated in thyrotoxicosis compared with that in euthyroid state. This phenomenon produces low $25 \mathrm{OHD}_{3}$ plasma levels in thyrotoxic subjects which initially may be normal or slightly increased depended from the vitamin $\mathrm{D}_{3}$ status in the thyrotoxic subjects. By continuous stimulatory action of increased thyroid hormones on liver enzymes the $25 \mathrm{OHD}_{3}$ plasma levels earlier or later decline in levels of hypo-or avitaminosis $\mathrm{D}_{3}$. The previously described biological events may explain the decreased intestinal calcium absorption of vitamin $\mathrm{D}_{3}$ and the osteomalacic component found in a percentage of thyrotoxic bone histology. For the blocking effects of allopurinol on liver enzymes function and possibly of other pharmaceutical products in relation to vitamin $\mathrm{D}_{3}$ bioactivation, available data are still lacking.
\end{abstract}

Keywords: 25-Hydroxyvitamin D; Thyroxin; Allopurinol; Microsomal Liver Enzyme’s Activity

\section{Introduction}

The introduction of many accurate methods for estimation of 25 hydroxyvitamin $\mathrm{D}_{3}\left(25 \mathrm{OHD}_{3}\right)$ blood levels in humans [1,2] allowed us to investigate the levels of this metabolite in thyrotoxicosis in an effort to dissolve some perplexing situations in this endocrinopathy. These situations include: 1) The disturbed calcium and phosphate metabolism in thyrotoxicosis and some unexplained osteomalacic changes in histology of thyrotoxic bones in a percentage of patients; 2) The examination of biotransformation of vitamin $\mathrm{D}_{3}$ in to $25 \mathrm{OHD}_{3}$ under the influence of thyroxin or allopurinol that as is known modulate the liver function's enzymes.

\section{Methods and Results}

The studies of biotransformation of antipyrine under increased levels of thyroxin or under administration of allopurinol as well the osteomalacic changes observed in thyrotoxic bones stimulated us to examine the biotransformation of vitamin $\mathrm{D}_{3}$ in hyperthyroidism [3]. In an article of 1977 we reported that in hyperthyroidism $25 \mathrm{OHD}_{3}$ plasma levels were lower comparing with that of healthy normal controls. Immediately other investigators conducted estimations of $25 \mathrm{OHD}_{3}$ plasma levels in thyrotoxicosis. Some of them confirmed our findings but others found normal or slightly increased values [4-9]. To explain the variety of $25 \mathrm{OHD}_{3}$ plasma levels in hy- 
perthyroidism we moved as follow. 1 mg vitamin $\mathrm{D}_{3}$ was injected in three male thyrotoxic subjects and in three male euthyroid. In addition the same was made in two thyrotoxic women and one euthyroid. All tested subjects were matched for age and body weight and injected the same period. $25 \mathrm{OHD}_{3}$ plasma levels were measured before and in post injection period every six hours for 48 hours. The post injection alteration occurring in each thyrotoxic or euthyroid subject formed the measure of vitamin $\mathrm{D}_{3}$ of 25 hydroxylase activity. In all thyrotoxic subjects an increase in $25 \mathrm{OHD}_{3}$ plasma levels was noted after the injection whereas these levels remained unchanged in healthy euthyroid controls. The acceleration of hydroxylation of vitamin $\mathrm{D}_{3}$ in to $25 \mathrm{OHD}_{3}$ in thyrotoxic subjects is depicted against of the health controls in Figures 1(a) and (b). From our observation was found that hydroxylation of vitamin $\mathrm{D}_{3}$ in $\mathrm{C}-25$ position is faster in thyrotoxicosis comparing with that of healthy subjects, became clear in six hours after injection, and its maximum after 36 hours with a fall thereafter. These data denotes that 25 hydroxylation of vitamin $\mathrm{D}_{3}$ in the liver proceeds 2.5 up to 8 times more rapidly in hyperthyroid individuals than in healthy euthyroid individuals [10]. In an other work we used a couple consisted from one thyrotoxic subject and one other healthy euthyroid control of the same age and body weight. In both subjects was given allopurinol $600 \mathrm{mg}$ daily for one week. After with-
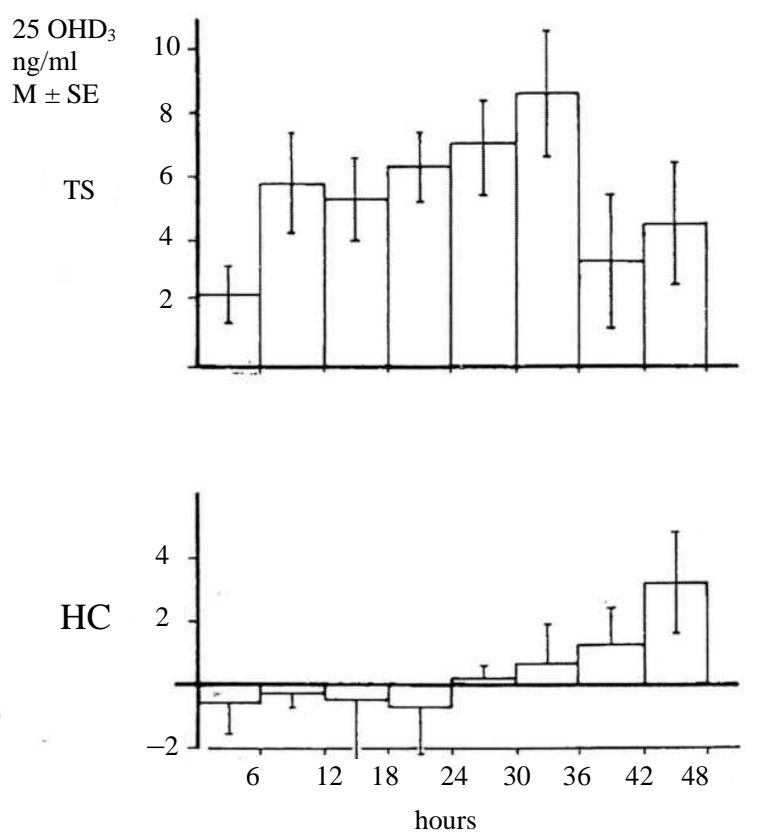

(a) drawal of allopurinol $1 \mathrm{mg}$ of vitamin $\mathrm{D}_{3}$ was injected i.v. in both subjects. $25 \mathrm{OHD}_{3}$ plasma levels were measured before the injection of Vitamin $\mathrm{D}_{3}$ and in six hours intervals post injection for 48 hours. The levels of $25 \mathrm{OHD}_{3}$ plasma levels in both individuals remained unchanged after the injection of vitamin $\mathrm{D}_{3}$ in comparison with that of preinjection level (Figure 2).

\section{Discussion}

When our observations were made the lower normal levels of $25 \mathrm{OHD}_{3}$ plasma levels were ill defined ranging from $<9 \mathrm{ng} / \mathrm{ml}$ to $<30 \mathrm{ng} / \mathrm{ml}$ [11]. So it was inconvenient to establish the diagnosis of vitamin $\mathrm{D}_{3}$ inadequacy. Last years a level 30 or $32 \mathrm{ng} / \mathrm{ml}$ approved as the lower limits in humans while the toxic levels as beyond $100 \mathrm{ng} / \mathrm{ml}$ or $150 \mathrm{ng} / \mathrm{ml}$ [12-18]. After definition of the new limits a new classification of the vitamin $\mathrm{D}_{3}$ status in humans was reported which is shown in Table $\mathbf{1}$. So indicated that hyperthyroid subjects are at risk for development insufficiency or deficiency of vitamin $\mathrm{D}_{3}$ especially in some cases where hyperthyroidism may run for a long time without the patient to seek medical consultation or to be without symptoms [19]. The incorporation of the accelerated vitamin $\mathrm{D}_{3}$ transformation in thyrotoxicosis explains with convincing manner the osteomalacic elements mentioned in hyperthyroidism long ago, as well their biochemical signs.
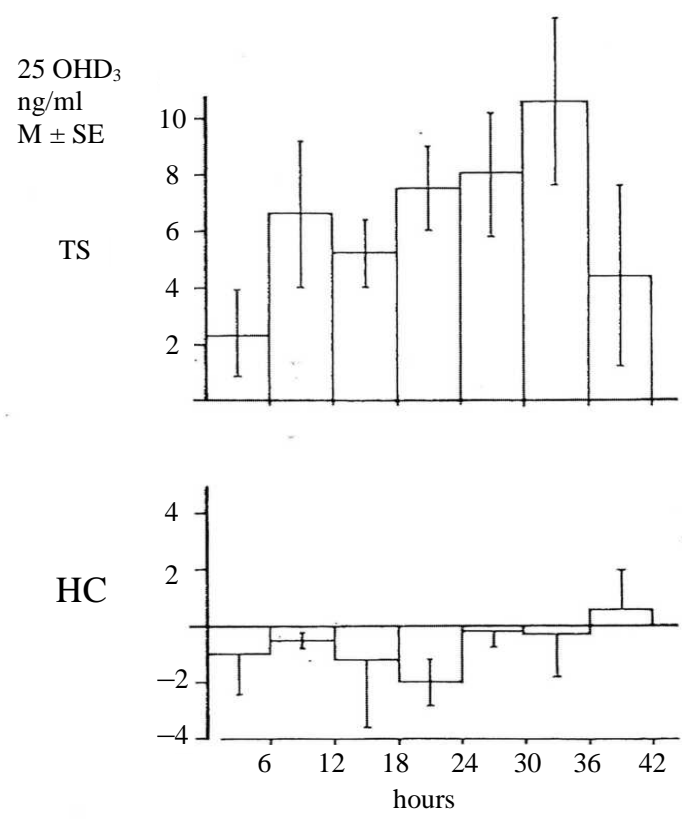

(b)

Figure 1. (a) Changes of $\mathbf{2 5 O H D}$ plasma levels in five thyrotoxic subjects (three males and two females) and in four euthyroid subjects (three males and one female) after i.v. administration of $\operatorname{lmg}$ of vit. $D_{3}$. In 42 hours $p<0.001$; In 48 hours p $<$ 0.001; TS = Thyrotoxic subjects; $\mathrm{HC}=$ healthy euthyroid controls; (b) Changes of $25 \mathrm{OHD}_{3}$ plasma levels in three thyrotoxic and in three euthyroid subjects only males after administrationof lmg of vit. $\mathrm{D}_{3}$. In 42 hours $\mathrm{p}<0.001$. In 48 hours $\mathrm{p}<0.001$. 

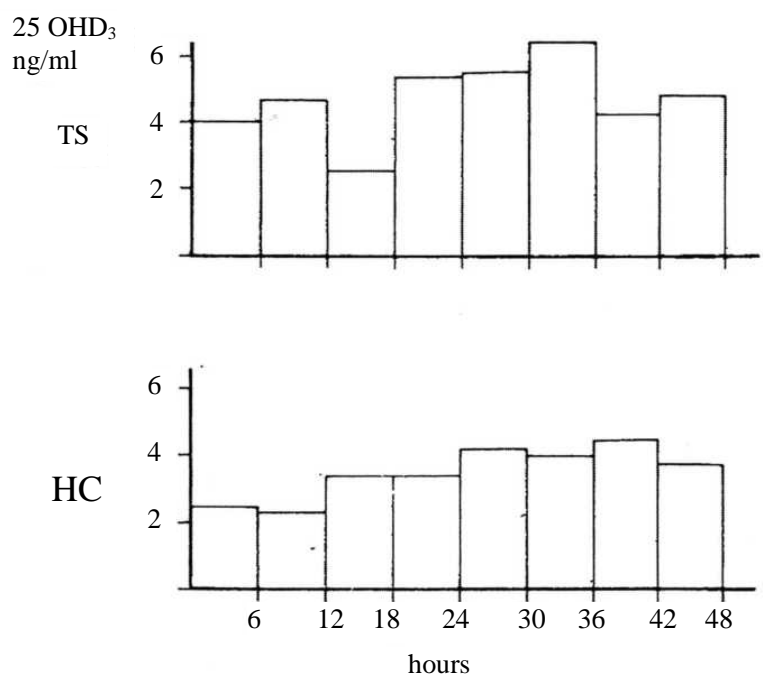

Figure 2. $250 \mathrm{HD}_{3}$ plasma levels in a couple of males after i.v. injection of $1 \mathrm{mg}$ of vit. $D_{3}$ (one TS and the other $\mathrm{HC}$ ) pretreated with allopurinol. In 42 hours $p<0.05^{*}$, in 48 hours $\mathbf{p}=$ NS.

Table 1. The vitamin $D_{3}$ status of the organism according to 25 hydroxyvitamin $D_{3}$ in blood levels.

\begin{tabular}{llc}
\hline 1) & $30-100 \mathrm{ng} / \mathrm{ml}(75-250 \mathrm{nmol} / \mathrm{L})$ & Normal \\
\hline 2$)$ & $21-29 \mathrm{ng} / \mathrm{ml}(52.5-72.5 \mathrm{nmol} / \mathrm{L})$ & Insufficiency \\
$3)$ & $<20 \mathrm{ng} / \mathrm{ml}(<50 \mathrm{nmol} / \mathrm{L})$ & Deficiency \\
$4)$ & $<15 \mathrm{ng} / \mathrm{ml}(<37.5 \mathrm{nmol} / \mathrm{l})$ & Unaccepted \\
\hline
\end{tabular}

Other situations which are at risk for inadequacy of vitamin $\mathrm{D}_{3}$ are shown in Table 2. In all these condition a testing of patients for their vitamin $\mathrm{D}_{3}$ status is needed and intervention with vitamin $\mathrm{D}_{3}$ when necessary having always in mind that in hyperthyroidism the circulating 1.25 dihydroxyvitamin $\mathrm{D}$ are low $[6,8]$. Therefore, in all cases in which thyroxin is increased or is administered (Table 2) always must be combined with vitamin $\mathrm{D}_{3}$. Our results show that the function of liver enzymes (CYP family) are found under the influence of some agents and in this case under the action of thyroxin or allopurinol. Thus thyrotoxic patients or patients with gout under treatment with allopurinol are needed careful manipulation especially when additional drugs are given.

When vitamin $D_{3}$ enter in the organism is "changed" since undergoes "hydroxylation" on C-25 position transformed in an active metabolite that is $25 \mathrm{OHD}_{3}$. This biotransformation of vitamin $\mathrm{D}_{3}$ takes place in microsomal liver enzymes by 25 hydroxylase (CYP2R1) belonging in microsomal in CYP family of P-450 cytochrome. Thyroxin is a potent stimulator of microsomal liver enzymes as has been demonstrated from the studies of antipyrine

\footnotetext{
*This may be due to the short period of administration of allopurinol.
}

Table 2. Situations that are at risk for insufficiency deficiency for vitamin $D_{3}$.

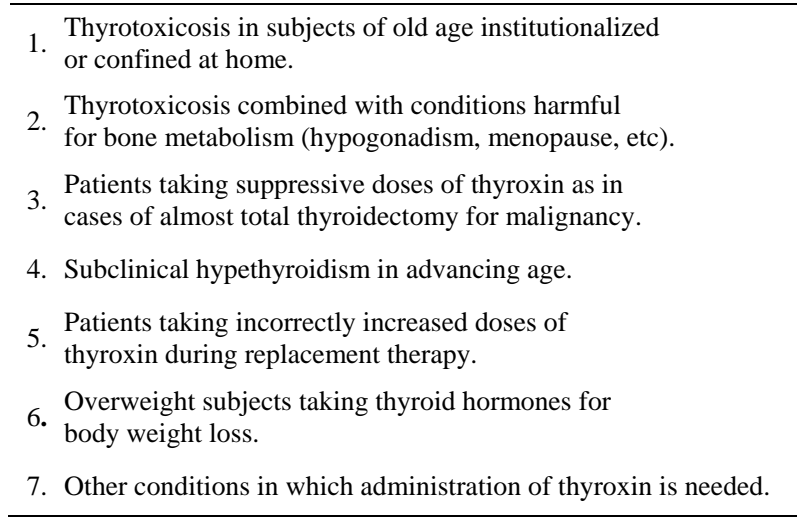

in thyrotoxicoses. Antipyrine is a substance that catabolized by biochemical transformation from microsomal liver enzymes. Crooks et al., (1973) found that the half life of the antipyrine in thyrotoxicosis $(7.9 \pm 0.6$ hours $)$ was lower comparing with that in normals $(10.8 \pm 0.4$ hours, $\mathrm{p}<0.001)$. Clearance values of antipyrine were higher in thyrotoxicosis than in normals $(2.6 \pm 0.2 \mathrm{~L} / \mathrm{h}$ against $2.2 \pm 0.1 \mathrm{~L} / \mathrm{h}, \mathrm{p}<0.05)$. In hypothyroid subjects the half life of antipyrine was higher than normals [20]. Eichelbaum et al. (1974) reported values of half life of antipyrine in thyrotoxic and hypothyroid patients before and after treatment and when euthyroidism had been established.

In thyrotoxic subjects the half life of antipyrine was found $7.9 \pm 1.0$ hours, in hypothyroid $17.3 \pm 1.1$ hours and in both groups $12.3 \pm 0.7$ and $12.0 \pm 0.5$ hours (normal limits) when euthyroidism was established [21]. Saenger et al. (1976) in thyrotoxic young boys reported half life of antipyrine 6.1 hours and in hypothyroid boys 34.5 hours. After therapy in thyrotoxic boys the half life of antipyrine increased to 10.1 hours while in hypothyroid decreased in 8.6 hours. The mean value of metabolic clearance decreased from 43 in $25 \mathrm{ml} / \mathrm{h}$ in thyrotoxic boys and increased from $11.7 \mathrm{in} 25 \mathrm{ml}$ in the hypothyroid boys [22]. The accelerated transformation of antipyrine in thyrotoxicosis denotes the stimulatory effect for thyroxin on liver enzyme function. Other substances as for example allopurinol exert suppressive action on liver enzymes. Thus Vesell et al. (1970) stated the mean \pm SD antipyrine half life was in healthy subjects $11.6 \pm 5.5$ hours before allopurinol administration, $19.1 \pm 4.4$ hours after two weeks on allopurinol, $31.0 \pm 6.5$ hours after four weeks on allopurinol and $11.2 \pm 2.7$ hours two weeks after discontinuation of allopurinol [23].

From the past century has been clearly established that in thyrotoxicosis exist a negative calcium balance since intestinal calcium absorption is depressed while the excretion of calcium by digestive system and urine is in- 
creased. On the contrary a percentage of thyrotoxic patients $27 \%$ shows mild hypercalcemia while a percentage $47 \%$ shows increased levels of ionized calcium [24-29]. Administration of vitamin $\mathrm{D}_{3}$ parenterally or per os does not reverse the negative calcium balance [30]. The phosphates in the blood are found increased although their level is depended from the phosphate intake by the food. The maximum tubular phosphate re absorption, the mean renal phosphate threshold are found increased while excretion of inorganic phosphate is decreased [31,32]. Another agent that is involved in bone's and mineral's metabolism in thyrotoxicosis is parathyroid hormone. Hyperparathyroidism has been found to coexist with thyrotoxicosis in a frequency greater with that of normal population. Parathyroid hormone blood levels have been reported as increased, normal or decreased [26,33], while the mean of alkaline phosphatase levels are significantly raised $[4,5,30]$. Description of macroscope bone changes are rare, since diagnosis and treatment early are offered for thyrotoxicosis. In a few cases of post mortem examination were reported prominent striae in the cortices of long bones, calvarium scapulae and iliac bones.

Histologically were found multiple spaces containing osteoclasts with clinical manifestations spontaneous fractures, vertebral compressions and demineralization of bones. Changes of bones structures are very common occurring in $70 \%-80 \%$ of cases. The prominent feature is stimulation of osteoclastic function (osteoclastosis) that results in bone loss in trabecular bones and increased cortical porosity due to increased diameter of haversian canals dilated by osteoclastic resorption. Surfaces covered by osteoid are increased and synthesize the picture of the high turnover osteoporosis in a proportion $30 \%$ since bone resorption exceeds bone formation. In a proportion of $20 \%$ there is not only increased osteoid seams but still their width corresponding to osteomalacia. Signs of osteitis fibrose are not present [34-37].

From the above mentioned data is indicated that thyroxin stimulates microsomal liver enzymes function which finally results in attenuation of $25 \mathrm{OHD}_{3}$ plasma levels below normal.

The increase of thyroxin in the blood from endogenous or exogenous sources influence through the abnormal low $25 \mathrm{OHD}_{3}$ plasma levels calcium metabolism and bone histology.

\section{Summary}

Vitamin $D_{3}$ after its entrance in the organism is hydroxylated on C25 by microsomal liver enzymes giving its main metabolite 25 hydroxyvitamin $D_{3}$. Thyroxin is a potent stimulator of the microsomal liver enzymes as has been indicated from the metabolism of antipyrine in hyperthyroid, euthyroid and hypothyroid states. Because of the continuous stimulatory action of thyroxin on microsomal liver enzymes 25 hydroxyvitamin $\mathrm{D}_{3}$ plasma levels may be initially normal or slightly increased but later decline in subnormal levels which disturb calcium and bone metabolism.

Allopurinol attenuates microsomal liver enzyme's activity as indicated by the study of metabolism of antipyrine under the influence of this substance. After administration of allopurinol in hyperthyroid and euthyroid state vitamin $\mathrm{D}_{3}$ hydroxylation on C25 remain unchanged.

This study regarding the metabolism of vitamin $\mathrm{D}_{3}$ in thyrotoxicosis was made segmental and now is presented integrated. The persons tested were coming from the Endocrine Unit of Military Hospital of Athens and all of them provided informed consent. The estimation of $25 \mathrm{OHD}_{3}$ plasma levels were made in Toronto Western Hospital by the method of Haddad and Chyou as well the statistical analysis. In this research did not used the normal limits of $25 \mathrm{OHD}_{3}$ in the blood established from 2004 and afterwards but the produced numbers of $25 \mathrm{OHD}_{3}$ plasma levels in thyrotoxics were always compared with that of corresponding euthyroid healthy controls.

\section{REFERENCES}

[1] J. G. Haddad and K. J. Chyu, "Competitive ProteinBinding Radioassay for 25-Hydroxycholecalciferol," Journal of Clinical Endocrinology \& Metabolism, Vol. 33, No. 6, 1971, pp. 992-995. doi:10.1210/jcem-33-6-992

[2] A. J. Ronver and K. O. O’Brien, "Hypovitaminosis D among Healthy Children in the United States," Archives of Pediatrics \& Adolescent Medicine, Vol. 162, No. 6, 2008, pp. 513-519. doi:10.1001/archpedi.162.6.513

[3] C. Velentzas, D. G. Oreopoulos, G. From, B. Porret and A. Rapaport, "Vitamin D Levels in Thyrotoxicosis," Lancet, Vol. 1, 1977, pp. 370-371. doi:10.1016/S0140-6736(77)91177-1

[4] H. J. W. Cleeve and R. F. Brown, "Plasma 25-Hydroxyvitamin D and Alkaline Phosphate Isoenzymes in Hyperthyroidism," Annals of Clinical Biochemistry, Vol. 15, No. 6, 1978, pp. 320-323.

[5] W. Hunstein, K. H. Gless, H. Schmidt-Gayk, G. V. Mittelstaedt and M. Hufner, "Alkaline Phosphatase and Plasma $25 \mathrm{OH}$ Vitamin D in Hyperthyroidism,” Hormone and Metabolic Research, Vol. 9, No. 6, 1977, pp. 532533. doi:10.1055/s-0028-1095592

[6] R. Bouillon, E. Muls and P. DeMoor, "Influence of Thyroid Function on the Serum Concentration of 1.25 Dihydroxyvitamin D,” Journal of Clinical Endocrinology \& Metabolism, Vol. 51, 1980, pp. 793-797. doi:10.1210/jcem-51-4-793

[7] E. Keck, H. Peerenboom, H. J. Graf, H. V. LilienfledToal and H. L. Kruskemper, "Vitamin D Metabolites in Hyperthyroidism,” Acta Endocrinologica, Vol. 96, 1980, p. 36. 
[8] I. A. MacFarlane, E. B. Mawer, J. Berry and J. Hann, "Vitamin D Metabolism in Hypethyroidism," Clinical Endocrinology, Vol. 17, No. 1, 1982, pp. 51-59.

[9] L. Mosekild, B. Lund, O. H. Sorensen, M. S. Christensen and F. Melsen, "25-Hydroxycholecalciferol in Hyperthyroidism,” Lancet, Vol. 1, 1977, pp. 806-807. doi:10.1016/S0140-6736(77)92995-6

[10] C. G. Velentzas, "Some Observation on Vitamin $D_{3}$ Metabolism in Thyrotoxicosis," Acta Vitamin Enzyme, Vol. 5, 1983, pp. 159-163.

[11] M. F. Holick, E. S. Siris, N. Binkley, M. K. Beard, A. Khan, J. T. Katzer, et al., "Prevalence of Vitamin D Inadequacy among Postmenopausal North Americans Women Receiving Osteoporosis Therapy," Journal of Clinical Endocrinology \& Metabolism, Vol. 90, No. 6, 2005, pp. 3215-3224. doi:10.1210/jc.2004-2364

[12] J. Adams and M. Hewison, "Update in Vitamin D," Journal of Clinical Endocrinology \& Metabolism, Vol. 95, No. 2, 2010, pp. 471-478. doi:10.1210/jc.2009-1773

[13] K. Heaney, "Functional Indices of Vitamin D Status and Ramifications of Vitamin D Deficiency,” American Journal of Clinical Nutrition, Vol. 80, No. 6, 2004, pp. 1706-1709.

[14] M. Holick, "MrOs Is D-Ficient,” Journal of Clinical Endocrinology \& Metabolism, Vol. 94, No. 4, 2009, pp. 1092-1093. doi:10.1210/jc.2009-0388

[15] M. F. Holick, "Vitamin D Deficiency," New England Journal of Medicine, Vol. 357, No. 3, 2007, pp. 266-281. doi:10.1056/NEJMra070553

[16] B. C. Hollis, "Circulating 25-Hydroxyvitamin D Levels Indicative of Vitamin D Sufficiency: Implication for Establishing a New Dietary Intake. Recommendation for Vitamin D,” Journal of Nutrition, Vol. 135, No. 2, 2005, pp. 317-322.

[17] D. W. Hollis and C. L. Wagner, "Normal Serum Vitamin D Levels," New England Journal of Medicine, Vol. 352, 2005, pp. 515-516. doi:10.1056/NEJM200502033520521

[18] E. Orwall, C. M. Nielsen, L. M. Marschall, L. Lambert, K. F. Holton, A. R. Hoffman, et al., "Vitamin D Deficiency in Older Men," Journal of Clinical Endocrinology \& Metabolism, Vol. 94, No. 4, 2009, pp. 1214-1222.

[19] C. G. Velentzas, "Vitamin D and Thyroid Hormones,” In: S. R. Malone, Ed., Vitamin D: Nutrition Side Effects and Supplements, 2009, pp. 175-184. doi:10.1210/jc.2008-1784

[20] J. Crooks, A. J. Hedley, C. MacNee and I. H. Stevenson, "Changes in Drug Metabolizing Ability in Thyroid Diseases," British Journal of Pharmacology and Chemotherapy, Vol. 49, 1973, pp. 156-157.

[21] M. Eichelbaum, G. Bodem, R. Gugler, C. SchneiderDeters and H. J. Dengler, "Influence of Thyroid Status on Plasma Half-Life of Antipyrine in Man,” New England Journal of Medicine, Vol. 290, No. 19, 1974, pp. 10401042. doi:10.1056/NEJM197405092901902

[22] P. Saenger, A. B. Rifkind and M. I. New, "Changes in Drug Metabolism in Children with Thyroid Disorders," Journal of Clinical Endocrinology \& Metabolism, Vol. 42, No. 1, 1976, pp. 155-159. doi:10.1210/jcem-42-1-155
[23] E. S. Vesell, I. Passananti and F. E. Green, "Impairment of Drug Metabolism in Man by Allopurinol and Nortriptyline,” New England Journal of Medicine, Vol. 283, No. 27, 1970, pp. 1484-1488. doi:10.1056/NEJM197012312832703

[24] J. D. Baxter and P. K. Bondy, "Hypercalcemia of Thyrotoxicosis,” Annals of Internal Medicine, Vol. 65, 1960, pp. 249-442.

[25] T. F. Davies and P. R. Larsen, "Thyrotoxicosis," 11th Edition, In: H. M. Kronenberg, S. Melmed, K. S. Polonsky and P. R. Larsen, Eds., Williams Textbook of Endocrinology, Saunders, 2008, pp. 333-375.

[26] D. Frizel, A. Malleson and V. Marks, "Plasma Levels of Ionized Calcium and Magnesium in Thyroid Disease," Lancet, Vol. 45, 1967, pp. 269-273.

[27] D. H. Smith, S. A. Frazer and G. M. Wilson, "Hyperthyroidism and Calcium Metabolism," Clinical Endocrinology \& Metabolism, Vol. 2, 1973, pp. 333-354.

[28] C. R. Kleeman, S. Tuttle and S. H. Basset, "Metabolic Observation in a Case of Thyrotoxicosis with Hypercalcemia," Journal of Clinical Endocrinology \& Metabolism, Vol. 18, No. 5, 1958, pp. 477-491. doi:10.1210/jcem-18-5-477

[29] P. Singhelakis, C. Alevizaki and D. Ikkos, "Intestinal Calcium Absorption in Hyperthyroidism,” Metabolism, Vol. 63, 1974, pp. 311-321. doi:10.1016/0026-0495(74)90049-3

[30] P. B. Cook, J. R. Nassim and J. Collins, "The Effects of Thyrotoxicosis upon the Metabolism of Calcium Phosphorus and Nitrogen," Quarterly Journal of Medicine, Vol. 28, No. 4, 1959, pp. 505-519.

[31] O. L. M. Bijvoet and C. L. H. Majoor, "The Renal Tubular Reabsorption of Phosphate in Thyrotoxicosis,” Clinica Chimica Acta, Vol. 11, 1965, pp. 181-183. doi:10.1016/0009-8981(65)90213-5

[32] B. Malamos, P. Sfikakis and P. Pandos, "The Renal Handling of Phosphate in Thyroid Disease," Journal of Endocrinology, Vol. 45, No. 2, 1969, pp. 269-273. doi:10.1677/joe.0.0450269

[33] A. M. Parfit and C. E. Dent, "Hyperthyroidism and Hypercalcemia,” Quarterly Journal of Medicine, Vol. 39, 1970, pp. 171-187.

[34] P. H. Adams, J. Jowsey, P. J. Kelly, L. Riggs, V. R. Kinney and J. D. Jones, "Effects of Hyperthyroidism on Bone and Mineral Metabolism in Man,” Quarterly Journal of Medicine, Vol. 36, 1967, pp. 1-15.

[35] J. Auwerx and R. Bouillon, "Mineral and Bone Metabolism in Thyroid Diseases. A Review," Quarterly Journal of Medicine, Vol. 60, 1986, pp. 737-752.

[36] L. Mosekilde, E. F. Eriksen and P. Charles, "Effects of Thyroid Hormone on Bone and Mineral Metabolism," Endocrinology and Metabolism Clinics of North America, Vol. 19, 1990, pp. 35-63.

[37] C. Velentzas and D. G. Oreopoulos, “Thyrotoxic Osteodystrophy: A Perplexing Type of Metabolic Bone Disease," Clinical and Investigative Medicine, Vol. 1, 1978, pp. 53-55. 